\title{
Contribuição da teoria histórico-cultural: um olhar para as interações em sala de aula a partir dos anais do ENEBIO
}

\section{Contribución de la teoría histórico-cultural: una mirada a las interacciones en el aula de los anales de ENEBIO}

\author{
Daniela Silva de Lourenço (danieladelourenco@ hotmail.com) \\ Universidade Federal da Fronteira Sul (UFFS) Campus Cerro Largo/RS \\ Sandra Maria Wirzbicki (sandra.wirzbicki@uffs.edu.br) \\ Universidade Federal da Fronteira Sul (UFFS) Campus Realeza/PR
}

\begin{abstract}
Resumo:O presente trabalho objetiva investigar a utilização do referencial teórico Histórico-Cultural a partir das interações em sala de aula, em trabalhos publicados nos Anais do Encontro Nacional de Ensino de Biologia (ENEBIO), nas seguintes edições: V ENEBIO (2014), VI ENEBIO (2016) e VII ENEBIO (2018), apontando a sua contribuição no ensino e aprendizagem, bem como as concepções dos autores sobre essa perspectiva teórica em pesquisas voltadas para o ensino de Ciências e Biologia. Em relação à metodologia, a pesquisa é qualitativa com caráter descritivo e documental. Para a análise dos dados, fez-se a opção pelos procedimentos de Análise Textual Discursiva (ATD). A análise dos trabalhos nos permitiu identificar duas categorias finais emergentes: Possibilidades de interação e mediação do outro através da linguagem e Desenvolvimento e aprendizagem de conceitos como processo Histórico-Cultural. A partir da construção e discussões das categorias, podemos aferir que, a aprendizagem tem relação com a constituição do sujeito, com o seu contexto, e que as interações entre pares de $/$ modo colaborativo, acompanhados de uma perspectiva metodológica problematizadora, são importantes indícios apontados pelos autores dos trabalhos que constituíram o corpus da análise no desencadeamento de interações no ensino e aprendizagem.
\end{abstract}

Palavras-chave: Desenvolvimento; Interação; Mediação; Ensino de Ciências e Biologia.

Resumen:Este artículo tiene como objetivo investigar el uso del marco teórico HistóricoCultural a partir de las interacciones en el aula, en trabajos publicados en las Actas del Encuentro Nacional de Biología Docente (ENEBIO), en las siguientes ediciones: V ENEBIO (2014), VI ENEBIO (2016) y VII ENEBIO (2018), señalando su contribución a la enseñanza y el aprendizaje, así como las concepciones de los investigadores sobre esta perspectiva teórica en la investigación orientada a la enseñanza de la Ciencia y la Biología. En cuanto a la metodología, la investigación es cualitativa con carácter descriptivo y documental. Para el análisis de los datos se eligió la opción de los procedimientos de Análisis Textual Discursivo (DTA). El análisis de las obras permitió identificar dos categorías finales emergentes: Posibilidades de interacción y mediación del otro a través del lenguaje y Desarrollo y aprendizaje de conceptos como proceso Histórico-Cultural. A partir de la construcción y discusión de las categorías, podemos 
verificar que, el aprendizaje está relacionado con la constitución del sujeto y con su contexto y que las interacciones entre pares de forma colaborativa acompañadas de una perspectiva metodológica problemática son importantes indicaciones señaladas por los autores de los trabajos. que constituyó el corpus de análisis en el desencadenamiento de interacciones en la enseñanza y el aprendizaje.

Palabras clave: Desarrollo; Interacción; Mediación; Docencia de Ciencias y Biología.

\section{INTRODUÇÃO}

Pensar em interações no ensino e aprendizagem, remete-nos a pensar na relação social entre sujeitos, no diálogo profícuo, na escuta atenta, na construção do conhecimento como um movimento solidário e democrático, em que o aluno tem vez e voz ativa e o professor compreende bem a sua função de ensino em sistematizar, acompanhar, orientar e intervir na aprendizagem.

Partindo da perspectiva teórica Histórico-Cultural de Vigotski $^{1}$ (2009), compreendemos que a atividade docente é uma prática recíproca, sendo quase impossível imaginá-la sem interações de diálogo, pois o desenvolvimento do estudante é sempre impulsionado pela aprendizagem e pelas interações que vão sendo estabelecidas. Com isso, inferimos que a aprendizagem é um processo colaborativo. Ao mesmo tempo que, ao interagir com o outro, nós desenvolvemos, contribuímos de igual modo, para que o outro se desenvolva.

Para tanto, ao compreender as interações em sala de aula, avançamos também na compreensão e reflexão das nossas próprias práticas docentes, uma vez que estamos nos permitindo melhorar e avançar em atividades metodológicas mais eficientes e interativas. Atingir tal grau de compreensão para qualificar processos de ensino e aprendizagem em Ciências e Biologia requer também conhecer como os demais profissionais da área têm se apropriado do referencial teórico Histórico-Cultural para trabalhar as interações em sala de aula.

Deste modo, este estudo tem por objetivo identificar a presença do referencial teórico Histórico-Cultural a partir das interações em sala de aula, em trabalhos publicados nos Anais do Encontro Nacional de Ensino de Biologia (ENEBIO), apontando a sua

\footnotetext{
${ }^{1}$ Optamos, neste trabalho, em usar a grafia Vigotski. A alteração da grafia poderá ocorrer apenas em citação referenciada por outros autores.

Recebido em: 18/01/2021

Aceito em: 24/02/2021
} 
contribuição no ensino e aprendizagem, bem como as concepções dos pesquisadores sobre essa importante perspectiva teórica.

A escolha dos Anais do Enebio, como pano de fundo da investigação, justifica-se por se tratar de um evento de ampla notoriedade e abrangência para o ensino de Ciências e Biologia, recebendo, em todas as suas edições, números expressivos de trabalhos, com pesquisas diversificadas que contribuem e apontam inúmeras possibilidades para pensar, repensar e compreender o ensino de Ciências e Biologia sob diferentes olhares e concepções teóricas. A pesquisa parte das seguintes questões problematizadoras: quais as repercussões do referencial teórico Histórico-Cultural em trabalhos publicados nos Anais do Enebio e quais as concepções dos pesquisadores sobre essa perspectiva teórica?

\section{APORTE TEÓRICO DA PESQUISA}

A Teoria Histórico-Cultural surge em um cenário de profundas mudanças e contradições políticas na União Soviética. O contexto histórico de tensões e desigualdades, no campo econômico e social, com predomínio de uma educação e economia elitista, foram algumas das motivações que desencadearam a Revolução Russa. Naquele período, a Rússia era um país em alguns aspectos extremamente atrasado com relação aos outros países industrializados da Europa, com uma população em sua maioria agrária e analfabeta (PRESTES, 2010).

Nesse contexto histórico, a Educação também passou por um período reconstrutivo, com necessidades de mudanças e avanços. Com isso, Vigotski, psicólogo, professor humanista, em início de carreira, funda uma escola em parceria com seus principais colaboradores Luria e Leontiev e um grupo de estudos que passou a ser chamado de troika, (VIGOTSKI, 2009). Vigotski, acompanhado de seus apoiadores, desenvolveram pesquisas que foram constituindo os postulados e dando moldes à Teoria HistóricoCultural.

O caminho percorrido por Vigotski foi alicerçado em muitos estudos teóricos e influenciado pelo próprio contexto histórico social da época ${ }^{2}$, assim: o materialismo histórico dialético Marxista; as contribuições de Engels sobre o trabalho humano e o uso

\footnotetext{
${ }^{2}$ Em 1917, teve início a Revolução Russa, período de intensos conflitos que resultaram na queda da monarquia Russa.
}

Recebido em: 18/01/2021

Aceito em: 24/02/2021 
de instrumentos; as visões filosóficas monistas de Espinoza (1979), sobre unidade, considerando por exemplo que afeto e intelecto não podem ser considerados separados e sim vistos como uma unidade a ser estudada. Tais pressupostos são as principais bases de estudo de Vigotski, ao trazer para o centro de seus estudos do Desenvolvimento Humano, a Consciência Humana (OLIVEIRA; REGO, 2010).

Os autores Newman e Holzman (1993), descrevem Vigotski como sendo um "cientista revolucionário", com um ritmo frenético de trabalho sem igual, apesar de ter uma vida precocemente interrompida (OLIVEIRA; REGO, 2010), seus estudos, tomando por exemplo o campo de ensino, até os dias atuais fundamentam aspectos importantes da aprendizagem. Neste sentido, é impossível contemplar em um único trabalho todo seu arcabouço teórico, com isso, optamos por discorrer neste trabalho sobre alguns conceitos da perspectiva Histórico-Cultural, tendo como aporte obras do próprio Vigotski (2009; 1991) e alguns dos principais postulados Vigotskianos defendidos por Rego (1995).

A autora Rego (1995) aponta alguns dos principais postulados defendidos por Vigotski que constituem todo seu arcabouço teórico. O primeiro diz respeito à relação do indivíduo com o seu meio social. Nessa perspectiva teórica, Vigotski (2009) defende a ideia de que somos geneticamente seres sociais, o sujeito tem uma história e uma cultura e os modos de pensar e interagir estão relacionados a sua cultura. $\mathrm{O}$ segundo postulado apontado por Rego (1995) transcorre do primeiro e trata do desenvolvimento das funções psíquicas, que vão se desenvolvendo a partir das interações do sujeito com o seu meio. Para Vigotski (2009), ao nascer, a criança traz consigo somente as funções psicológicas elementares, como, por exemplo, a atenção involuntária. Para atingir as funções psicológicas superiores, como a atenção voluntária, ela precisa do acompanhamento e de interações com outros indivíduos. Na maioria das vezes, essa socialização primária ocorre dentro do contexto familiar.

Porém, a criança, em fase de desenvolvimento, vai cada vez exigir mais dos sujeitos adultos que a cercam. Em determinado momento, as relações familiares já não são capazes de suprir todas as necessidades de aprendizagem da criança, ela precisa de um acompanhamento mais especializado. A partir daí, a escola desempenha um importante papel, permitindo esta continuidade. A escola, para a criança, passa a ser um novo espaço 
social de interações e de construção de conhecimento e o professor, por sua vez, é o adulto que vai orientando esse processo. Vigotski (2001, p.331) considera que "[...] na escola a criança não aprende o que sabe fazer sozinha, mas o que ainda não sabe e lhe vem a ser acessível em colaboração com o professor e sob sua orientação".

O processo de acompanhamento da criança por alguém mais experiente e/ou com níveis de desenvolvimento mais avançado, envolve mediação, outro postulado defendido por Vigotski. Tal pressuposto "[...] é fundamental na perspectiva sócio-histórica, justamente porque é através dos instrumentos e signos que os processos de funcionamento psicológico são fornecidos pela cultura" (REGO, 1995, p. 43).

Retomando as funções psíquicas superiores, na perspectiva de Vigotski (2009), essas se desenvolvem a partir da linguagem, da interação com o outro e dos estímulos provocados pelo meio. Esse desenvolvimento, a partir da linguagem, é impulsionado pelo uso dos elementos mediadores: os signos e instrumentos. Deste modo, para Vigotski (2009, p. 161),

[...] todas as funções psíquicas superiores têm como traço comum o fato de serem processos mediatos, melhor dizendo, de incorporarem à sua estrutura, como parte central de todo o processo, o emprego de signos como meio fundamental de orientação e domínio nos processos psíquicos.

De igual modo, os instrumentos têm como principal função o controle das ações sobre o objeto, contribuindo no desenvolvimento das funções psicológicas superiores, uma vez que, acompanhado dos signos, potencializam o desenvolvimento. Na aprendizagem, o emprego da palavra pelo professor, carregada de significados, ao explicitar um conceito é um signo mediador. O recurso didático que o professor utiliza para auxiliar no ensino são os instrumentos, exemplo disso, pode ser o livro didático e/ou o próprio planejamento do professor que contribui para a realização de sua atividade docente.

Desta forma, na escola, o professor, na condição de sujeito orientador do ensino e aprendizagem, faz uso de recursos que vão facilitar tal processo. As interações de diálogo são o ponto inicial que permitem manter a participação interativa dos estudantes durante as atividades desenvolvidas por ele. Vigotski (2009, p. 480) considera que "[...] o diálogo é um discurso constituído de réplicas, é uma cadeia de reações". Para tanto, quando o 
professor estabelece com seus alunos interações de diálogo, ele está permitindo e disponibilizando espaço para o aluno perguntar, responder, interagir, opinar e são essas reações que atribuem sentido à aprendizagem.

Outro importante postulado de Vigotski (2009) foi o desenvolvimento de conceitos. Ao relatar suas investigações sobre esses estudos, o autor registrou algumas dificuldades iniciais, ficando mais evidentes na "[...] ausência de uma metodologia experimental elaborada que permitisse penetrar fundo no processo de formação de conceitos e estudar a sua natureza psicológica" (p. 151). Tais inquietações levaram Vigotski (2009), mais tarde, a investigar com suporte de um estudo experimental o processo genético de formação de conceitos, com diferentes faixas etárias chegando a concluir que,

[...] o desenvolvimento dos processos que finalmente culminam na formação de conceitos começa na fase mais precoce da infância, mas as funções intelectuais que, numa combinação específica, constituem a base psicológica do processo de formação de conceitos amadurecem, configuram-se e se desenvolvem somente na puberdade (VIGOTSKI, 2009, p.167).

Para Vigotski (2009, p. 161), “[...] o desenvolvimento dos conceitos espontâneos e científicos - cabe pressupor - são processos intimamente interligados, que exercem influências um sobre o outro". Há uma interdependência entre ambos, em que, para desenvolver o conceito científico/conceito verdadeiro é preciso partir de um conceito espontâneo/pseudoconceito. Atingir esse nível de associação entre os conceitos exige muitas interações e trocas dialógicas.

Para compreender o movimento de apropriação do conceito científico pelo sujeito, Vigotski (2009) desenvolveu o conceito de internalização, o que para o autor (1991, p. 40), “[...] chamamos de internalização a reconstrução interna de uma operação externa. Um bom exemplo desse processo pode ser encontrado no desenvolvimento do gesto de apontar”. A autora Góes (1991, p. 18) contribui nesse sentido, ao afirmar que, “[...] as funções psicológicas, que emergem e se consolidam no plano da ação entre sujeitos, tornam-se internalizadas, isto é, transformam-se para constituir o funcionamento interno". Na perspectiva de Vigotski (1991), quando o sujeito for capaz de se apropriar e internalizar o conceito científico, ele atinge o nível mais completo da aprendizagem, uma vez que, sua compreensão conceitual é ampliada permitindo-lhe habilidades para criar generalizações. 
Os estudos desenvolvidos por Vigotski, que constituíram a perspectiva teórica denominada Histórico-Cultural, são intensos tanto na riqueza do material que foi produzido em uma curta passagem de vida, quanto na sua profundidade ao também ousar compreender a constituição interna do sujeito. Nos processos de ensino e aprendizagem, tal perspectiva teórica redimensionou o olhar do professor para com seu estudante, ao reforçar a ideia de que o desenvolvimento tem relação com a constituição do sujeito e que aspectos relacionados a sua história, cultura e contexto social, são indissociáveis e impulsionam interações, que, consequentemente, favorecem à aprendizagem.

\section{PROCEDIMENTOS METODOLÓGICOS}

A presente pesquisa é de abordagem qualitativa, com base na proposta de Lüdke e André (2001), com caráter descritivo e do tipo bibliográfica. As pesquisas de abordagem qualitativa são consideradas, pelos autores (2001), como aquelas que visam a produzir e aprofundar compreensões por meio de dados descritivos. Dessa forma, nessa pesquisa, foi realizado um levantamento de trabalhos publicados nos Anais do Enebio em suas últimas três edições: V Enebio (2014), VI Enebio (2016) e VII Enebio (2018). Esse recorte temporal se justifica em razão dos inúmeros trabalhos publicados em cada uma das edições do evento. Para a análise, a opção se deu pela Análise Textual Discursiva (ATD), proposta por Moraes e Galiazzi (2007). De modo geral, a ATD “corresponde a uma metodologia de análise de dados e informações de natureza qualitativa com a finalidade de produzir novas compreensões sobre os fenômenos e discursos analisados" (MORAES; GALIAZZI, 2007, p.2).

Para a seleção dos trabalhos nos Anais do ENEBIO (2014), utilizamos os descritores: "Interação" "Interações" “Teoria Histórico-Cultural” e "Histórico-Cultural". Foram utilizados como critério de seleção aqueles trabalhos que indicavam em todos os seus campos de busca algum dos descritores. Ao fazer essa constatação, foi realizada a leitura na íntegra desses trabalhos a fim de encontrar relações entre as interações/interação e a fundamentação teórica Histórico-Cultural. Assim, identificamos, nos Anais do ENEBIO (2014), oito trabalhos dos 568 publicados.

O mesmo movimento de busca foi realizado nos Anais do VI Enebio (2016), sendo que dos 699 trabalhos publicados, apenas cinco apresentavam a temática em evidência. 
De igual forma, a busca se deu também nos Anais do VII Enebio (2018), dos 902 trabalhos publicados, apenas um retratava a temática proposta. A relação dos 14 trabalhos (APÊNDICE A) seguiu uma ordem cronológica de publicação. Para os trabalhos que se somaram ao mesmo ano de publicação, deu-se a prioridade, respeitando a sequência de organização dos próprios Anais. Os trabalhos encontram-se melhores apresentados e descritos no Quadro 1.

Quadro 1 - Relação dos trabalhos selecionados

\begin{tabular}{|c|c|c|}
\hline Anais/Ano & Titulo dos trabalhos & $\begin{array}{l}\text { Identificação do trabalho }(\mathrm{T}) / \\
\text { ano de publicação e autores }\end{array}$ \\
\hline V ENEBIO (2014) & $\begin{array}{l}\text { Proposta de uma unidade de análise } \\
\text { para a materialidade da cognição }\end{array}$ & $\mathrm{T}_{1 \text { (2014) }}$ Coutinho et al. \\
\hline V ENEBIO (2014) & $\begin{array}{l}\text { Desvendando o DNA de Allium cepa } \\
\text { para aprender genética }\end{array}$ & $\mathrm{T}_{2 \text { (2014) }}$ Piotrowski et al. \\
\hline V ENEBIO (2014) & $\begin{array}{l}\text { Evolução, aprimoramento e } \\
\text { progresso: concepções em discussão } \\
\text { na sala de aula do ensino médio }\end{array}$ & $\mathrm{T}_{3 \text { (2014) }}$ Oliveira e Silva \\
\hline V ENEBIO (2014) & $\begin{array}{l}\text { Concepções de estudantes do ensino } \\
\text { fundamental sobre fatores bióticos e } \\
\text { abióticos e suas implicações ao } \\
\text { ensino de ecologia. }\end{array}$ & $\mathrm{T}_{4(2014)}$ Schneider e Silva \\
\hline V ENEBIO (2014) & $\begin{array}{l}\text { "Explorando" a cidade de } \\
\text { Cariacica/ES: uma experiência de } \\
\text { educação patrimonial realizada com } \\
\text { os professores }\end{array}$ & $\mathrm{T}_{5 \text { (2014) }}$ Carvalho \\
\hline V ENEBIO (2014) & $\begin{array}{l}\text { O potencial educativo do Frottage na } \\
\text { exposição "o mundo gigante dos } \\
\text { micróbios" }\end{array}$ & $\mathrm{T}_{6(2014)}$ Franco, Iszlaji e Oliveira \\
\hline V ENEBIO (2014) & $\begin{array}{l}\text { Ensino e formação escolar: algumas } \\
\text { implicações de modelos de ensino } \\
\text { vivenciados } \\
\text { educativos. }\end{array}$ & $\mathrm{T}_{7 \text { (2014) }}$ Costa Beber, Kogler e Frison \\
\hline V ENEBIO (2014) & $\begin{array}{l}\text { Estratégia teórico-metodológica para } \\
\text { o ensino de botânica na educação } \\
\text { escolar indígena. }\end{array}$ & $\mathrm{T}_{8(2014)}$ Ramos e Silva \\
\hline VI ENENIO (2016) & $\begin{array}{l}\text { Complexidade dos processos de } \\
\text { ensino e aprendizagem na inserção de } \\
\text { conteúdos escolares na situação de } \\
\text { estudo. }\end{array}$ & $\mathrm{T}_{9 \text { (2016) }}$ Costa-Beber e Bianchi \\
\hline VI ENEBIO (2016) & $\begin{array}{l}\text { A pesquisa como princípio educativo } \\
\text { articulador das aprendizagens de } \\
\text { conteúdos escolares }\end{array}$ & $\begin{array}{l}\mathrm{T}_{10} \text { (2016) Frizon, Madke e } \\
\text { Wyzykowski }\end{array}$ \\
\hline VI ENENIO (2016) & A linguagem baseada em símbolos & $\mathrm{T}_{11(2016)}$ Schneider e Silva \\
\hline
\end{tabular}




\begin{tabular}{|l|l|l|}
\hline & $\begin{array}{l}\text { para a aprendizagem de cadeia } \\
\text { alimentar no nível fundamental }\end{array}$ & \\
\hline VI ENEBIO (2016) & $\begin{array}{l}\text { Proposta de uma sequência didática } \\
\text { para a compreensão das } \\
\text { características evolutivas dos filos } \\
\text { zoológicos }\end{array}$ & $\mathrm{T}_{12 \text { (2016) Serpa e Ramos }}$ \\
\hline VI ENEBIO (2016) & $\begin{array}{l}\text { Ensino de biologia e perspectiva } \\
\text { crítica: a teoria histórico-cultural }\end{array}$ & $\mathrm{T}_{13(2016)}$ Coelho et al. \\
\hline VII ENEBIO (2018) & $\begin{array}{l}\text { Um olhar sobre os processos de } \\
\text { ensino e de aprendizagem em um } \\
\text { projeto de trabalho sobre o tema } \\
\text { tecnologia. }\end{array}$ & $\begin{array}{l}\mathrm{T}_{14} \text { (2018) Oliveira, Ferreira e } \\
\text { Sangiogo }\end{array}$ \\
\hline
\end{tabular}

Fonte: As autoras, 2021.

Os 14 trabalhos estão identificados, no decorrer do artigo, como: $\mathrm{T}_{1 \text { (2014) }}$ Coutinho et al., $\mathrm{T}_{2}$ (2014) Piotrowski et al., $\mathrm{T}_{3}$ (2014) Oliveira e Silva e, assim, sucessivamente. Os trabalhos selecionados constituíram o corpus de análise. Moraes e Galiazzi (2007) classificam como sendo a matéria-prima da pesquisa e da investigação. Assim, realizamos uma leitura de cada um dos trabalhos selecionados com fins de seguir as etapas previstas na ATD e identificar possíveis categorias de análise, bem como novas compreensões acerca da temática.

A primeira etapa prevista na ATD é a unitarização ou desmontagem do corpus de análise. Na concepção de Moraes e Galiazzi (2007), “[...] a desmontagem dos textos é mostrada como processo recursivo de mergulho nos significados dos textos analisados, processo em que se exige que o pesquisador se assuma em suas interpretações" (p. 2). Para a realização dessa etapa, foi necessário fazer uma leitura na íntegra dos trabalhos, a fim de encontrar relações com os descritores e organizá-los por meio de recortes.

A segunda etapa da ATD é a da síntese, também chamada de categorização. Para os autores Moraes e Galiazzi (2007, p. 2), “[...] a categorização constitui movimento de síntese, de construção de sistemas de categorias capazes de expressarem as novas aprendizagens e compreensões construídas no processo da análise”. Nesta etapa da ATD, definimos as unidades de sentido de cada um dos excertos do corpus de análise e chegamos a um total de 36 unidades. Essas unidades nos permitiram agrupar os trabalhos em categorias: Iniciais, Intermediárias e Finais.

Na categorização inicial, as unidades de sentido constituíram 18 categorias. Dessas, 
sete constituíram as categorias Intermediárias, das quais somente duas compuseram a categorização Final (QUADRO 2), quais sejam: Possibilidades de interação e mediação do outro através da linguagem e Desenvolvimento e aprendizagem de conceitos como processo Histórico-Cultural.

Quadro 2 - Categorias finais com a relação de trabalhos selecionados

\begin{tabular}{|l|l|}
\hline \multicolumn{2}{|c|}{ Categorias Finais } \\
\hline $\begin{array}{r}\text { Possibilidades de interação e mediação do outro } \\
\text { através da linguagem }\end{array}$ & $\begin{array}{c}\text { Desenvolvimento e aprendizagem de conceitos } \\
\text { como processo Histórico-Cultural }\end{array}$ \\
\hline $\mathrm{T}_{1(2014)}$ Coutinho et al.; $\mathrm{T}_{2}(2014)$ Piotrowski, et al.; & $\mathrm{T}_{3(2014)}$ Oliveira e Silva; $\mathrm{T}_{4(2014)}$ Schneider e Silva; \\
$\mathrm{T}_{5(2014)}$ Carvalho; $\mathrm{T}_{6(2014)}$ Franco, Iszlaji e Oliveira; & $\mathrm{T}_{7}(2014)$ Costa Beber, Kogler e Frison; $\mathrm{T}_{8}(2014)$ \\
$\mathrm{T}_{10}(2016)$ Frizon, Madke e Wyzykowski; $\mathrm{T}_{11}(2016)$ & Ramos e Silva; $\mathrm{T}_{9(2016)}$ Costa-Beber e Bianchi \\
Schneider e Silva; $\mathrm{T}_{12}(2016)$ Serpa e Ramos; $\mathrm{T}_{13}$ & \\
(2016) Coelho et al.; $\mathrm{T}_{14}(2018)$ Oliveira, Ferreira e & \\
Sangiogo & \\
\hline
\end{tabular}

Fonte: As autoras, 2021.

\section{RESULTADOS E DISCUSSÕES}

O último movimento da ATD foi o da descrição e interpretação, a fim de construir textos reorganizados (metatextos). Moraes e Galiazzi (2007) definem o metatexto como sendo uma escrita de um texto que é articulada a partir da categorização e atribuem " [...] como uma das finalidades de construir um sistema de categorias, o encaminhamento de um metatexto, expressando uma nova compreensão do fenômeno investigado" (p. 93). A partir desse movimento de análise, construímos os resultados que são apresentados através da discussão das duas categorias, com aporte no referencial Histórico-Cultural.

\subsection{Possibilidades de interação e mediação do outro através da linguagem}

$\mathrm{Na}$ escrita reflexiva deste metatexto procuramos destacar possibilidades de interação e mediação do outro através da linguagem e como essas questões numa perspectiva Histórico-Cultural contribuem para o ensino e aprendizagem de Ciências e Biologia.

Partindo da concepção de Vigotski (2009), em que o desenvolvimento humano tem relações inerentes com o contexto social e interacionista, considerarmos que a aprendizagem ocorre em dois planos. No plano externo/social, a aprendizagem ocorre de forma colaborativa, há sempre a figura do outro mais experiente organizando e intermediando o processo educativo. 
O outro plano ocorre em meio interno/intrapessoal, de forma individualizada, em que as representações mentais construídas no âmbito externo/social passam a ser internalizadas e, assim, reconstruídas pelo sujeito. No $\mathrm{T}_{13}$ Coelho et al. (2016, p. 5723) propõem que “[...] o homem é um ser histórico-cultural; moldado pela cultura que ele próprio cria e determinado pelas relações com o outro, tendo a linguagem um papel central nesse processo". Neste sentido, para que as interações sejam estabelecidas em sala de aula, no $\mathrm{T}_{14}$ Oliveira, Ferreira e Sangiogo (2018, p. 340) apontam haver “[...] a necessidade de estimular a aprendizagem para o progresso do desenvolvimento cognitivo, cabendo ao docente a mediação". De igual modo, no T3 Oliveira e Silva (2014, p. 5711) corroboram ao afirmar que "[...] as características próprias da constituição histórica do sujeito ocorrem pela mediação do outro através da linguagem".

Ao discorrer sobre os elementos mediadores, no $\mathrm{T}_{1}$ Coutinho et al. (2014, p. 1931) destaca que "[...] são entendidos como ferramentas ou signos que servem como meios pelos quais o indivíduo exerce ação sobre o mundo ou sofre a ação de fatores sociais, culturais e históricos”. A partir da contribuição trazida, no $T_{1}$ é possível elucidar que os signos e instrumentos contribuem para o exercício pleno da atividade docente em sala de aula e também para o desenvolvimento do estudante, uma vez que ampliam as possibilidades de compreensão científica sobre o objeto a ser estudado. Mas, para que isso venha a ocorrer, faz-se necessário que todos os sujeitos envolvidos no processo de aprendizagem, vivenciem momentos de interação simultânea.

Deste modo, no $\mathrm{T}_{6}$ Franco, Iszlaji e Oliveira (2014, p. 6915) destacam que, “[...] os signos fazem parte do funcionamento psicológico da criança, como formas de representação, no qual estão intrinsecamente ligados à cultura, incluem a linguagem e o desenho". Na perspectiva de Vigotski (2009), a linguagem na representação da palavra é reconhecida por um signo de sublimidade. Ao falar, o estudante está, ao mesmo tempo, interagindo com o professor ou com um outro mais experiente. Essas trocas recíprocas favorecem a organização do pensamento, da significação conceitual e, consequentemente, da aprendizagem.

O exercício da fala e das trocas interativas favorecem a transição das funções intermentais/fala social para as funções intramentais/fala egocêntrica (VIGOTSKI, 2009). 
Quando o estudante atinge a última função, ele também se torna autorregulador de suas próprias funções mentais, adquirindo autonomia para pensar e controlar suas ações.

Enquanto isso, os instrumentos, elementos culturalmente construídos pelos sujeitos, contribuem para qualificar o emprego dos signos. Nesse sentido, os autores, em $\mathrm{T}_{7}$ Costa Beber, Kogler e Frison (2014, p. 4816) destacam que, "[...] o uso de instrumentos diferenciados nas atividades de sala de aula promove interações e corresponsabiliza o estudante pela sua aprendizagem, concordando com as ideias histórico-culturais". Neste sentido, em $T_{5}$ Carvalho (2014), ao discorrer sobre os espaços não formais de ensino, defende que muitos destes,

[...] são capazes de auxiliar na ampliação de conceitos e na construção do conhecimento por meio da interação com os objetos que os constituem e que estimulam a significação descrita por Vygotsky como importante para compreensão do mundo e sobre ele atuar. Os instrumentos utilizados em uma aula de campo possibilitam que o ensino de diferentes práticas seja executada (CARVALHO, 2014, p. 5834).

Compreender o desenvolvimento do sujeito e as relações individuais e sociais implicadas nesse processo, requer compreender o papel da escola no desenvolvimento humano, uma vez que, no T 10 Frizon, Madke e Wyzykowski (2016, p. 1722), destacam que "[...] a aprendizagem escolar, além de promover a aquisição dos conteúdos ou habilidades específicas, consiste também em uma via de desenvolvimento psíquico". Assim, abrem-se possibilidades de compreender que a escola e seu espaço de aprendizagem cumprem uma função que vai além do ensino conteudista e formativo, mas é também um espaço de socialização especializado, pois promove e estimula o desenvolvimento contínuo do sujeito, habilitando-lhe também a compreender e transformar seu contexto, sua história e sua própria cultura. No $\mathrm{T}_{11} \mathrm{Schneider}$ e Silva (2016), discorrem sobre o ensino e aprendizagem e exemplificam como essas relações em sala de aula podem ser vivenciadas, ao afirmar que:

[...] o espaço social é um dos principais contribuintes para o desenvolvimento cognitivo dos alunos, pois quando eles estão em pares um oferece assistência para o outro para ajudar a completar a tarefa através das interações colaborativas (SCHNEIDER; SILVA, 2016, p. 3693).

Ainda, no $\mathrm{T}_{11}$, as autoras apontam como possibilidades de interação em sala de aula o agrupamento colaborativo entre pares, em que um colega mais experiente contribui para o desenvolvimento do outro. Na perspectiva de Vigotski (2009), tal possibilidade de 
interação em sala de aula elucida o postulado da Zona de Desenvolvimento Proximal (ZDP), que diz respeito a todo conhecimento que o sujeito ainda não sabe fazer sozinho, mas que pode aprender a fazer com a ajuda do outro em fase de desenvolvimento mais avançado.

Já os autores do $\mathrm{T}_{2}$ Piotrowski et al. (2014, p. 6958) apontam a abordagem metodológica problematizadora como possibilidade de promover interação em sala de aula, uma vez que "[...] infere aos alunos a possibilidade de interação no processo de construção da aula, proporcionando assim um ambiente de questionamentos, instigando os alunos à participação". A problematização nas relações de ensino e aprendizagem induzem o sujeito a ser interativo, a participar e colaborar ativamente na construção/compreensão do conhecimento científico. Deste modo, as autoras do $\mathrm{T}_{10}$ Frizon, Madke e Wyzykowski (2016) também contribuem ao destacar que,

[...] com base no referencial histórico-cultural, consideramos importante compreender as interações dos sujeitos e, assim, desenvolvê-las de forma consciente e intencionalmente construtiva nos espaços de convivência, como os das salas de aula (FRIZON; MADKE; WYZYKOWSKI, 2016, p. 1726).

Assim, nesse metatexto, indicamos a importância dos elementos mediadores na interação entre sujeitos, uma vez que esses interagem, respondendo aos estímulos provocados pelo contexto que, neste trabalho, atribui destaque à sala de aula. As interações entre pares de modo colaborativo e a perspectiva metodológica problematizadora são importantes indícios apontados pelos trabalhos que compõe o corpus da análise no desencadeamento de interações no ensino e aprendizagem. No próximo metatexto, discorremos sobre o desenvolvimento de conceitos no ensino e aprendizagem com olhar específico a compreensões fundamentadas pela teoria HistóricoCultural.

\subsection{Desenvolvimento e aprendizagem de conceitos como processo Histórico-Cultural}

Na construção desse metatexto, buscamos explicitar a concepção dos autores sobre o desenvolvimento e aprendizagem de conceitos como processo Histórico-Cultural, apontando como os pesquisadores se apropriaram do referencial teórico supracitado para fundamentar o desenvolvimento e aprendizagem de conceitos em sala de aula.

Alguns dos desafios do professor em sala de aula referem-se a compreender os processos de ensino e aprendizagem e, consequentemente, contribuir para que seu 
estudante desenvolva uma melhor aprendizagem conceitual. Outro desafio, refere-se ao conhecimento internalizado pela teoria para que possa ser desenvolvido na prática e usado pelo sujeito para compreender, a partir de um conhecimento científico, as transformações que circundam o seu contexto social.

Partindo desse pressuposto, pesquisadores têm buscado amparo teórico na perspectiva Histórico-cultural, pois, segundo $\mathrm{T}_{7}$ Costa Beber, Kogler e Frison (2014, p. 4806), "[...] o ensino que atualmente vem sendo apontado para melhorar a educação escolar e, por isso, muito discutido em eventos da área educacional é o histórico-cultural”. Deste modo, ampliar os modos de compreensão do desenvolvimento de conceitos como processo histórico, nas palavras expressas no T 8 Ramos e Silva (2014, p. 5711), “[...] pode nos auxiliar grandemente na compreensão do processo de construção do conceito no estudante e nas aulas de Biologia”.

A partir dessa visão teórica, há de se compreender que o desenvolvimento perpassa, inicialmente, pelos conhecimentos empíricos/espontâneos, os quais constituem a história e a cultura do sujeito, propiciando o desenvolvimento dos conhecimentos concretos/científicos. No $\mathrm{T}_{7}$ Costa Beber, Kogler e Frison (2014, p. 4806) corroboram postulados vigotskianos ao afirmar que “[...] é sob a perspectiva da história e da cultura que o conhecimento é produzido e o indivíduo se desenvolve, tanto na teoria quanto na prática". Esse desenvolvimento não ocorre de modo isolado e sim em meio às interações sociais. Sobre isso, as autoras Schneider e Silva (2014, p. 4729), no T 4 destacam que “[...] é na troca de informações com outros sujeitos e consigo próprio que os conhecimentos vão sendo internalizados, permitindo a formação da própria consciência”.

Esse desenvolvimento acompanha o sujeito em todo seu processo de aprendizagem. Isso é identificado por Vigotski (2009), ao afirmar que a criança, ao nascer, possui apenas as funções elementares e necessita do acompanhamento e estímulo de um adulto para desenvolver as funções mentais superiores. No $\mathrm{T}_{4}$ Schneider e Silva (2014) propõem que “[...] o desenvolvimento e a aprendizagem estão inter-relacionados desde o nascimento da criança" (p. 4727).

Tal compreensão, também foi destacada no T4 de Schneider e Silva (2014), em que é mencionado a importância do professor considerar o sujeito como um todo, constituído 
de uma bagagem histórica, social e cultural, que traz para a sala de aula uma riqueza empírica que requer ser desenvolvida, de modo que a partir de sua experiência social possa desenvolver uma aprendizagem mais científica. Esse modo de compreender o sujeito tem sido alicerce para trabalhar a aprendizagem de conceitos em sala de aula, pois, no $\mathrm{T}_{3}$ Oliveira e Silva (2014) também destacam que,

[...] a compreensão de que os conceitos cotidianos presentes nas falas dos estudantes possuem um enraizamento histórico permite ao professor compreender as ligações históricas que constituem as relações entre as estruturas conceituais no estudante e desta forma intervir pedagogicamente para o sujeito possa ressignificar conceitos internalizados de modo equivocado! (OLIVEIRA; SILVA, 2014, p. 5717).

As ligações históricas que acompanham o desenvolvimento dos estudantes, quando pedagogicamente exploradas pelo professor, contribuem para a aprendizagem. No $\mathrm{T}_{9}$ Costa Beber e Bianchi (2016) corroboram ao destacar que "[...] partindo do cotidiano para trabalhar os conceitos científicos, dificilmente os alunos não conseguiram ver a aplicabilidade destes conhecimentos" (p. 768).

Para tanto, as experiências vivenciadas pelos estudantes em seu contexto social são norteadoras do planejamento e ensino do professor. Só há diálogo e interação em sala de aula quando o professor for capaz de criar relações com o conceito científico que deseja trabalhar, com a realidade, a cultura e a história dos sujeitos. No T 8 Ramos e Silva (2014, p. 2088) destacam que “[...] a aprendizagem de conceitos científicos não exclui os conceitos cotidianos, mas eleva estes para um nível de conhecimento mais elaborado". Ao considerar esses aspectos, o professor está potencializando seus estudantes, mostrando que o conhecimento desenvolvido em sala de aula tem relação com suas vivências e que esses só precisam ter ampliado seu desenvolvimento. Os autores do $\mathrm{T}_{9}$ Costa Beber e Bianchi (2016) contribuem ao destacar que,

[...] aproveitando-se de uma situação da vivência dos alunos, os professores evitam cometer um equívoco bastante comum, o desenvolvimento de conceitos que não condizem com a realidade histórica-sócio-cultural dos alunos e que não são vivenciados na prática (COSTA-BEBER; BIANCHI, 2016, p. 783).

E por trás de todo processo de ensino e aprendizagem está o trabalho e planejamento do professor, pois, quando bem sistematizado, coloca o sujeito em condição interativa de aprender e essa condição contribui para seu desenvolvimento, uma vez que, ao participar e interagir, ele está respondendo aos estímulos e avançando no desenvolvimento das 
funções superiores. No T 9 Costa Beber e Bianchi (2016, p. 772) apostam que “[...] uma reorganização curricular contextualizadora, interdisciplinar e vivenciada no cotidiano, pode contribuir para a formação docente, uma vez que se constitui como um desafio em prol da apropriação do modelo histórico-cultural”.

Finalizamos esse metatexto em defesa de que a compreensão, desenvolvimento e aprendizagem de conceitos como processo Histórico-Cultural, em sala de aula, requer reconhecer a constituição do sujeito como um todo e sua subjetividade. O conhecimento científico faz parte do contexto social do estudante e esse contexto contribui para o desenvolvimento e compreensão do conceito científico. Não é algo somente abstrato, vai ter sempre conexão com a realidade do sujeito. Se o professor conseguir que seu estudante compreenda essa relação, a aprendizagem ganha mais sentido e reforça sua própria essência de reciprocidade.

\section{CONSIDERAÇÕES FINAIS}

A partir dos resultados construídos, podemos afirmar que os postulados de Vigotski fazem-se presentes nas relações de ensino e aprendizagem e que os modos de pensar, agir e construir conhecimento tanto pelo professor quanto pelo estudante são socialmente, historicamente e culturalmente compreendidos como processos correspondentes que determinam o desenvolvimento.

A pesquisa nos leva a compreender que os meios pelos quais aprendemos e nos desenvolvemos tem relação com as interações sociais, com a mediação simbólica, instrumental e com as estratégias de ensino que são propostas pelo professor. Daí a importância do planejamento do ensino, na orientação da aprendizagem, na organização do pensamento, na significação do conceito e no processo de elaboração e internalização do conhecimento científico.

A aprendizagem de conceito concebida pelos autores dos trabalhos que compuseram o corpus da análise como processo Histórico-Cultural é atribuída ao fato de não ser uma ação descontextualizada e abstrata e sim um fazer intencionado e contextualizador. Deste modo, o ensinar, parte de conhecimentos já existentes, mas que ainda não foram bem desenvolvidos e elaborados pelo sujeito. Com isso, a mediação e a interação com o outro vão atribuindo significados e sentidos ao conceito e, por 
conseguinte, são reelaborados. Neste percurso, o professor desempenha função primordial ao intervir e intermediar a aprendizagem.

Podemos, ainda, estabelecer reflexões de que o processo de ensino e a aprendizagem são distintos, porém, interdependentes. Não são processos de improvisos que vão sendo construídos a partir de ações não intencionadas. Ensinar e aprender requer ampliar visões de contexto, conhecer a constituição do sujeito e reconhecê-lo como ser social e histórico que, através da interação com o outro, vai conquistando seu espaço, reafirmando-se e se apropriando de sua cultura. Enfim, desenvolvemo-nos em processo contínuo, colaborativo e repleto de interações.

\section{AGRADECIMENTOS}

À Coordenação de Aperfeiçoamento de Pessoal de Nível Superior - Brasil (CAPES) - Código de Financiamento 001.

\section{REFERÊNCIAS}

ESPINOSA, Baruch. Ética. 2 ed. Tradução e notas de Joaquim de Carvalho. São Paulo: Abril Cultural, 1979.

GÓES, M.C.R. A abordagem microgenética na matriz histórico-cultural: uma perspectiva para o estudo da constituição da subjetividade. Cad. CEDES vol. 20, Campinas: SP, Apr. 2000.

LÜDKE, M.; ANDRÉ, M. E. D. A. Pesquisa em educação: abordagens qualitativas. São Paulo: EPU, 38p. 2001.

MORAES, R.; GALIAZZI, M do. C. Análise Textual Discursiva. 2a ed. Ijuí: Editora Unijuí, 2007.

NEWMAN, F., HOLZMAN, L. Lev Vygotsky: Cientista revolucionário. Tradução: Taylor e Frances / Routledge. São Paulo: Edições Loyola. 1993.

OLIVEIRA, M. K.; REGO, T. C. Contribuições da perspectiva histórico-cultural de Luria para a pesquisa contemporânea. Educação e Pesquisa. São Paulo, v. 36, n. especial, p. 107-121, 2010.

PRESTES, Z. R. Quando não é a mesma coisa: análise de traduções de Lev Semionovitch Vigotski no Brasil: repercussões no campo educacional. 2010. 295 f. Tese (Doutorado em Educação) - Universidade de Brasília, Brasília, 2010.

REGO, T. C. Vygotsky - uma perspectiva histórico-cultural da educação. Petrópolis, 
RJ: Vozes, 1995.

VYGOTSKY, L. S. A formação social da mente: o desenvolvimento dos processos psicológicos superiores. Tradução: José Cipolla Netto et al. 6. ed. São Paulo: Fontes, 1991.

VIGOTSKI, L.S. A construção do pensamento e da linguagem. Tradução: Paulo Bezerra. São Paulo: Martins Fontes, 2009.

\section{APÊNDICE A - TRABALHOS SELECIONADOS PARA A ANÁLISE}

CARVALHO, M. P. "Explorando" a cidade de Cariacica/ES: uma experiência de educação patrimonial realizada com os professores. In: Anais do Encontro Nacional de Ensino de Biologia, 2014. São Paulo. São Paulo: SBEnBio, 2014.

COELHO, L. J.; CANCELLARA, C.H.P.; SOUZA, D. C; de.; ANDRADE, T. Y. I; LIPORINI, T. Q.; CAMPOS, L. M. L.; DINIZ, R. E. da S. Ensino de biologia e perspectiva crítica: a teoria histórico-cultural. In: Anais do Encontro Nacional de Ensino de Biologia, 2016. Maringá, PR. Maringá: SBenBio, 2016.

COSTA BEBER, L. C.; KOGLER, J. T. S.; FRISON, M. D. Ensino e formação escolar: algumas implicações de modelos de ensino vivenciados em processos educativos.In: Anais do Encontro Nacional de Ensino de Biologia, 2014. São Paulo. São Paulo: SBEnBio, 2014.

COSTA-BEBER, L. C.; BIANCHI, V. Complexidade dos processos de ensino e aprendizagem na inserção de conteúdos escolares na situação de estudo. In: Anais do Encontro Nacional de Ensino de Biologia, 2016. Maringá, PR. Maringá: SBenBio, 2016.

COUTINHO, F. A; SILVA, F. A. R e; MATOS, S. A; LISBOA, D. do P. Proposta de uma unidade de análise para a materialidade da cognição. In: Anais do Encontro Nacional de Ensino de Biologia, 2014. São Paulo. São Paulo: SBEnBio, 2014.

FRANCO, S. D; ISZLAJI, C; OLIVEIRA, A. D de. O potencial educativo do Frottage na exposição "o mundo gigante dos micróbios". In: Anais do Encontro Nacional de Ensino de Biologia, 2014. São Paulo. São Paulo: SBEnBio, 2014.

FRISON, M. D; MADKE, P; WYZYKOWSKI, T. A pesquisa como princípio educativo articulador das aprendizagens de conteúdos escolares. In: Anais do Encontro Nacional de Ensino de Biologia, 2016. Maringá, PR. Maringá: SBenBio, 2016.

OLIVEIRA, C. A. I.; FERREIRA, M.; SANGIOGO, F.A. Um olhar sobre os processos de ensino e de aprendizagem em um projeto de trabalho sobre o tema tecnologia. In: Anais do Encontro Nacional de Ensino de Biologia, 2014. Belém, PA. Belém: SBenBio, 2018.

OLIVEIRA, M. A.; SILVA, L.H. de. A. Evolução, aprimoramento e progresso: concepções em discussão na sala de aula do ensino médio. In: Anais do Encontro Nacional de Ensino de Biologia, 2014. São Paulo. São Paulo: SBEnBio, 2014.

PIOTROWSKI, S. M; GÜLLICH. R. I da. C; THOMAS, J. F. MELO, J. B de. M. 
Desvendando o DNA de allium cepa para aprender genética. In: Anais do Encontro Nacional de Ensino de Biologia, 2014. São Paulo. São Paulo: SBEnBio, 2014.

RAMOS, F.Z.; SILVA, L.H. de. A. Estratégia teórico-metodológica para o ensino de botânica na educação escolar indígena. In: Anais do Encontro Nacional de Ensino de Biologia, 2014. São Paulo. São Paulo: SBEnBio, 2014.

SCHNEIDER, M. C.; SILVA, L. H. de A. Concepções de estudantes do ensino fundamental sobre fatores bióticos e abióticos e suas implicações ao ensino de ecologia. In: Anais do Encontro Nacional de Ensino de Biologia, 2014. São Paulo. São Paulo: SBEnBio, 2014.

SCHNEIDER, M. C; SILVA, L. H. de A. A linguagem baseada em símbolos para a aprendizagem de cadeia alimentar no nível fundamental. In: Anais do Encontro Nacional de Ensino de Biologia, 2016. Maringá, PR. Maringá: SBenBio, 2016.

SERPA, J. D. M; RAMOS, F. Z. Proposta de uma sequência didática para a compreensão das características evolutivas dos filos zoológicos. In: Anais do Encontro Nacional de Ensino de Biologia, 2016. Maringá, PR. Maringá: SBenBio, 2016. 